Estudios Románicos, Volumen 30, 2021, pp. 303-313

ISSN: 0210-4911

eISSN: $1989-614 \mathrm{X}$

DOI: https://doi.org/10.6018/ER.457471

\title{
EN LA LUCHA FINAL, LA ARTIFICIOSA Y FALLIDA NOVELA DE RAFAEL CHIRBES
}

(En la lucha final, Rafael Chirbes' contrived and failed novel)

\author{
Jacobo Llamas Martínez* \\ IES Xesús Taboada Chivite
}

\begin{abstract}
Rafael Chirbes refused to reissue his novel En la lucha final, considering it failed, and the publishing house Anagrama has so far respected that will. There was only one edition published in 1991. This article studies the literary reasons why the author may have made this decision. Many of them also explain Chirbes's convictions and career as a writer.
\end{abstract}

Keywords: Rafael Chirbes; En la lucha final; Los viejos amigos; Life; Work; Diary.

Resumen: Rafael Chirbes se negó a reeditar su novela En la lucha final por considerarla fallida, y la editorial Anagrama ha respetado por ahora esa voluntad, de manera que únicamente se ha publicado una edición en 1991. En este artículo se estudian las razones literarias por las que el autor pudo haber tomado esta decisión; muchas de las cuales justifican las convicciones y la trayectoria posterior de Chirbes como escritor.

Palabras clave: Rafael Chirbes; En la lucha final; Los viejos amigos; Vida; Obra; Diario.

En la lucha final probablemente sea la novela menos leída, mencionada y estudiada de las editadas por Rafael Chirbes, quien renegó de ella desde su publicación. Si bien esto fue usual por parte del escritor, debido a su insatisfacción y consabida inseguridad hacia todo lo que escribía, su juicio sobre la obra se mantuvo firme, por lo que se negó a reeditarla y la única edición existente continúa siendo la publicada en el año 1991 por la editorial Anagrama.

Chirbes procuró no referirse a En la lucha final para que quedase como una especie de borrón olvidado en su trayectoria literaria. En los ensayos sobre su oficio de escritor

* Dirección para correspondencia: Jacobo Llamas Martínez. Departamento de Lengua Castellana y Literatura. IES Xesús Taboada Chivite. Avenida de Portugal, 116, 32600, Verín (Ourense). (jacobo.llamas@edu.xunta.gal). 
- Chirbes (2002) y (2010) - , aportó informaciones sobre las fuentes, la intertextualidad y la génesis de todas sus novelas, pero entre ellas apenas hay menciones explícitas a En la lucha final' . De hecho, la publicación al año siguiente de La buena letra (1992) reorientó la forma de novelar del autor, quien, en vez de un protagonista masculino con pretensiones de ser escritor que narra situaciones asimilables al presente o a un pasado próximo de su biografía como en Mimoun (1988) y en En la lucha final, recurrió a un personaje femenino para evocar su infancia y el pasado de su familia. Esto se iría ampliando en sus novelas siguientes, Los disparos del cazador (1994), La larga marcha (1996) y La caída de Madrid (2000), en las que el dialogismo amplió la visión sobre la posguerra y el franquismo, y diseminó las vivencias, convicciones y contradicciones del propio Chirbes, quien no volvió a centrarse en un tiempo muy próximo al de la publicación de la novela hasta en Los viejos amigos (2003), «hermanada», según Español (2019: 236), con En la lucha final por el marco temporal y los asuntos tratados. Pero a ello habría que añadir la ciudad de Madrid como espacio; el tipo de personajes - antiguos militantes comunistas en torno a la cuarentena en En la lucha final y la cincuentena en Los viejos amigos-; la complejidad del punto de vista, y la manera de intercalar las voces de «Amelia» y «Ricardo» al final de la primera parte (Chirbes 1991: 103-103), que evocan o anticipan los monólogos interiores de los personajes de Los viejos amigos ${ }^{2}$. Herralde (2015) llegó a sugerir a Chirbes que encabezase los monólogos de esta última con el nombre del personaje correspondiente para facilitar la lectura, pero el escritor se negó por creer que se deducía fácilmente.

La sofisticación estructural y el artificio estilístico de En la lucha final desdibuja un tanto la impugnación política y social que implica el acomodo, la desidia y la renuncia a los ideales revolucionarios, igualitarios y solidarios de los personajes, y son las novelas siguientes de Chirbes las que contribuyen a esta interpretación. La larga marcha y La caída de Madrid manifiestan con mayor crudeza la desazón y la degradación moral que supuso la guerra y la dictadura de Franco, lo que explica la actitud oportunista y mendaz de los personajes de Los viejos amigos educados bajo ese régimen. Su actitud ejemplifica - siempre de acuerdo con Chirbes - el fracaso vital, político e ideológico del escritor y de su generación, representado por las lacras particulares de cada uno de ellos: desde Carlos, el autor que vendería a su padre, «si viviera», por escribir una buena novela, hasta Pedro, para quien «la revolución es el mal de la noche» (Chirbes 2003: 11), pasando por el resto de personajes, de los que se ocupan en detalle López Bernasocchi y López de Abiada (2011c)3. Esta diatriba continúa en Crematorio (2007) y En la orilla (2013), pero ya está presente en En la lucha final, donde el innominado personaje que narra la novela ilustra el fracaso personal de Chirbes, y los de Amelia, Carlos, Pedro Ruibal, Concha, José Bardón, Silvia, Ricardo Alcántara, Santiago e incluso los esporádicos de Brines y Brull muestran las envidias, celos, rivalidades y traiciones de su generación. Sus nombres

\footnotetext{
1 La única que he encontrado figura en una charla de junio de 2001 en el Museo Thyssen-Bornemisza de Madrid: «hay referencias a él [el pintor Francis Bacon] en Los disparos del cazador y En la lucha final» (Chirbes 2015 [2002]: 63).

2 De manera más anecdótica, convendría sumar a los argumentos anteriores el uso de la expresión «viejos amigos»: «-Ricardo, ten cuidado con estos hijos de puta. No esperes nada de ellos. Ya no son tus viejos amigos. Solo les queda la apariencia de lo que fueron» (Chirbes 1991: 70).

3 Para los personajes de Crematorio y La larga marcha véanse López Bernasocchi y López de Abiada (2011a y 2011b).
} 
y circunstancias (profesión, trabajo, convicciones, deseos) recuerdan a los de Los viejos amigos: el cinismo y el deseo de medro de Amelia, la codicia y el poder de Carlos, el bravucón y frustrado Pedro, las aspiraciones de clase de Concha, el mentiroso Ricardo Alcántara, Santiago, el heroinómano celoso... ${ }^{4} \mathrm{El}$ mismo Chirbes confirmó en su diario inédito A ratos perdidos la afinidad de asuntos, tono e intención de En la lucha final y de Los viejos amigos al rememorar el pulso estilístico que supuso la escritura de la primera ${ }^{5}$ :

Sólo En la lucha final me planteó tantos problemas como me está planteando la novela que escribo [Los viejos amigos]. Tengo voces, personajes, pero me faltan los cinco puntos esenciales que hacen que un texto sea una novela: ¿quién cuenta?, ¿qué cuenta?, ¿por qué lo cuenta?, ¿a quién se lo cuenta?, ¿para qué se lo cuenta? Pero es que lo que quiere contar no puede haber ningún narrador capaz de asumirlo, porque eso sería como asumir un proyecto colectivo, cuando la novela lo que quiere contar es precisamente que no lo hay (Chirbes $A$ ratos perdidos, 2: 73) ${ }^{6}$.

En entradas posteriores del diario, Chirbes se refirió a En la lucha final como una novela fallida, que compartía los mismos defectos que Crematorio - «una novela hueca, grandilocuente» (Chirbes $A$ ratos perdidos, 5: 93) - y adujo el haber tenido en cuenta la opinión de demasiadas personas como una de las razones por las que no respondió a sus expectativas o no fue de su agrado: «De mis primeros escritos, entregaba folios a los amigos, pidiéndoles su opinión. No he vuelto a hacerlo desde en En la lucha final, la segunda novela que escribí, un libro que se frustró quizá por tener los oídos demasiado abiertos» (Chirbes $A$ ratos perdidos, 5: 299). Probablemente, personas próximas al escritor se reconocieron en situaciones y personajes, y Chirbes debió de optar por atender las sugerencias que le formularon, algo que no sucedió en las novelas siguientes, en las que arremetió contra sí mismo y contra personas próximas o reconocibles de su entorno familiar, universitario, amistoso y laboral ${ }^{7}$.

\footnotetext{
$4 \quad$ Valls (2014-2015: 130-132) ofrece una síntesis y una certera valoración de En la lucha final.

5 El diario está disponible para su consulta en la Fundació Rafael Chirbes (véase la bibliografía para más detalles).

6 Durante el proceso de redacción de En la lucha final, concretamente el 20 de diciembre de 1987, Chirbes ( $A$ ratos perdidos, 1: 148) anotó: «Tengo a grandes rasgos el tema de la próxima novela: algo de lo que quisiera contar. Es decir, me falta todo, aunque creo que, si lo sé organizar, eso puede estar en estos cuadernos que he ido poco a poco llenando con citas ajenas».

$7 \quad$ A este respecto es muy significativa la dedicatoria de La larga marcha (1996): «A Constantino [Bértolo], que me lee, A Ernesto, Vicente, Carmen y Elena (sin hace) [Elena Cabezalí, se supone, amiga de Chirbes y vocal de la Fundació del autor]» (Chirbes 1996: s. p. [7]). Desde entonces, la única dedicatoria de Chirbes en sus libros es la destinada a Carlos Blanco Aguinaga, con quien mantuvo contacto (correspondencia, llamadas telefónicas y encuentros) desde que participó en un seminario dirigido por el profesor en los años setenta. Val (2014-2015: 287) explica: «De 1976 a 1978 forma, junto a un grupo de amigos, un seminario con Carlos Blanco Aguinaga. "Estaban Isabel Romero - a quien echo de menos, falleció hace unos años-, Ana Puértolas, Manuel Rodríguez Rivero, Luis María Brox, Constantino Bértolo, Carmen del Moral y Alfredo Taberna. Nos dedicamos a estudiar la crítica periodística de entonces - el Informaciones Literario, El País-, y a trabajar en la poesía de Gil de Biedma y de César Vallejo, y sobre algunas novelas: Imán, Doctor Faustus, La consagración de la primavera... Eran discusiones a vida o muerte y Blanco tenía una paciencia de santo con nuestra altiva ignorancia"». En A ratos perdidos, Chirbes muestra además su abatimiento por el alejamiento de ciertas amistades — la de Constantino Bértolo es una de ellas («brillante reflexión de mi (ex) amigo Bértolo sobre El Quijote», Chirbes A ratos perdidos, 6: 54)_, pero al mismo tiempo se jacta de la incorruptibilidad de su criterio, rasgo que Chirbes convirtió en su principal aval como escritor e intelectual.
} 
Más interesantes que las circunstancias y motivos personales que pudieron haber llevado al autor a suavizar o a no expresar todo lo que hubiese deseado en En la lucha final por amistad, respeto o pudor, resultan los de carácter literario. A la luz de la trayectoria, figura y juicios de Chirbes se deducen las razones genéricas, estructurales y estilísticas por las que el escritor consideró En la lucha final una novela malograda. La primera de ellas puede ser el aire de novela negra, de intriga o misterio. Las conversaciones del ignoto personaje y narrador de la historia, un escritor primerizo que busca tema para su segunda novela y aspira a la repercusión cultural y social del matrimonio formado por Carlos y Amelia y de su círculo de amigos, van desvelando las relaciones perniciosas entre ellos y exponen el engaño de Ricardo Alcántara y lo sucedido la noche del asesinato de Carlos. Ambos hechos suponen casi el arranque de la trama: «Puede decirse que esta historia empezó el día en que Ricardo llamó a Amelia para decirle que acababa de regresar a Madrid. Fue el primer ladrillo que el destino colocó en la tumba de Carlos; la primera palada de tierra sobre el grupo» (Chirbes 1991: 22).

Al final de la primera parte de la novela se resuelve el engaño al revelar el narrador cómo Ricardo Alcántara conoce y se apropia durante su estancia en Manila de los papeles escritos por el difunto Manuel Weizer (Chirbes 1991: 106-115). Entre ellos figuran la novela Una moneda en el aire y el libro de relatos El espejo de mármol que Ricardo asegura escribir, y se introduce la figura de Tomás Beltrán, conocedor de esos papeles y gracias a quien el resto de personajes descubren el plagio tal como se especifica en la tercera parte de En la lucha final: «Pedro sabía que Brines quería a Ricardo aún menos que él. Le pidió por teléfono que saliera a la calle, buscase la librería más cercana y adquiriese el libro de un tal Tomás Beltrán. "Se titula Una moneda en el aire [...]» (Chirbes 1991: 144-145).

En esta tercera parte también se aclaran las circunstancias del otro misterio de la novela, el involuntario asesinato de Carlos por parte de Santiago, anticipado al comienzo («pienso en Santiago, a quien no conozco, en el cuchillo que le robó a Pedro y que usó para matar a Carlos», Chirbes 1991: 16):

Carlos se despertó al escuchar ruidos. Debió de pensar que se trataba de Amelia [...]. Santiago lo contó así en el juicio: «Salió desperezándose. Los faldones de la camisa le colgaban fuera del pantalón. Al verme, no retrocedió. Gritó algo y avanzó tambaleándose como si estuviese borracho. Era como si fuese a matarme sólo con la mirada. Cuando sintió el cuchillo, se quedó quieto, y entonces me dio pena» (Chirbes 1991: 177).

La segunda parte de En la lucha final reproduce el diario de Ricardo Alcántara; en él anota los pormenores de su encuentro con M. W. (Manuel Weizer), refiere el mecanografiado de El espejo de mármol y la intención de retomar el contacto con sus antiguos amigos de facultad en Madrid, con «A.» (Amelia) en especial, ante los que quiere reaparecer como un talentoso escritor merced a los textos de Weizer:

Mecanografío El espejo de mármol. Estoy bloqueado. De vez en cuando me encuentro con alguna palabra que no entiendo y soy incapaz de adivinarla [...] Reflexión pesimista: no sirvo ni para mecanógrafo de M. W. [...] Escucho en una 
entrevista por la radio a A., vieja amiga de la Universidad. No sé muy bien cómo, pero tengo que acabar regresando a ese grupo [...] Volver al grupo de A., a los viejos amigos de la Facultad, cargado con los manuscritos de M. W. significa traspasar una parte de su poder a mi cuenta (Chirbes 1991: 130-131).

Todos estos avatares, propios de un thriller con toques folletinescos y sentimenta${ }^{1 e s}{ }^{8}$, son un reflejo más de las viciadas relaciones de los personajes, cuyas rencillas, ventajismo e infidelidades gradualmente reveladas inciden en el suspense de En la lucha final y propician la fatal muerte de Carlos:

Durante mucho tiempo, Santiago había sido el único en saber que Pedro y Amelia eran amantes porque la había seguido a ella con frecuencia: cuando salía con Ricardo y también cuando iba sola, o acudía a casa de Pedro. Santiago guardó sus descubrimientos en secreto. Un día podrían llegar a serle útiles y, además, constituían el contrapunto en el que se sentía vengador de la relación de Ricardo con Amelia, de las relaciones que mantenían todos los componentes del grupo (Chirbes 1991: 169).

A esta trama policiaca o de misterio se añade la inquietud generada por el desconocido narrador, que aspira al reconocimiento como novelista y cuya biografía y reflexiones remiten a la figura de Chirbes después de la publicación de Mimoun: «Yo todavía no era nadie [...] y ni mi foto ni mi nombre aparecían en ningún sitio [...] [Brines] se había leído mi libro, publicado apenas unas semanas antes. Era el primero y no llevaba camino de convertirse en ningún éxito de ventas, aunque había sido bien recibido por los críticos» Chirbes (1991: 10-11).

Estos elementos hacen de En la lucha final una novela de intriga o suspense con rasgos de novela negra, una tendencia destacada por las historias de la literatura en la narrativa española del último cuarto del siglo xx. En la lucha final trasluce, además, otras características resaltadas por esas mismas historias: un cierto cosmopolitismo, exotismo u orientalismo; la temática desencantada y marginal — más recordada hoy por el cine que por la literatura - ; y el cliché metaliterario, ya que del epílogo de la obra se deduce que lo relatado por el innominado narrador se convertirá, tras una revisión y reescritura, en su siguiente obra (Chirbes 1991: 187-190) ${ }^{9}$. Las tres partes en las que se

8 La figura de Amelia, a quien los personajes masculinos desean y los femeninos envidian, concita la mayor parte de esos pasajes sentimentaloides: «"Carlos vivía muy aferrado a su infancia”, dice Brines, "había algo en su infancia que lo había marcado y que a mí me fue descubriendo. Resulta digno de reflexión que, cuando Amelia se empeñó en iniciar un descabellado romance conmigo, Carlos no se enojara nunca. Incluso estoy convencido de que, desde entonces, me apreció más. Continué trabajando para él en la galería y hasta puedo decir que vino más por las noches y que bebimos más que nunca juntos y que me hizo confidencias"» (Chirbes 1991: 78).

9 Según Valls (2014-2015: 130), el resultado de la novela escrita por el narrador sería «lo que un posmoderno de hoy tacharía de novela reportaje». Sanz Villanueva (1992: 260) consideró: «La metanovela es una actitud especial dentro de una más genérica que puede calificarse, con término también extendido por la moda, metacultural». Aunque muchas historias de la literatura comentan la cuestión, remito a Sanz Villanueva (1992) porque su síntesis, que toma planteamientos de trabajos suyos anteriores (de 1988 y 1990), es casi contemporánea a la publicación de En la lucha final y recoge juicios y nociones que el escritor pudo haber considerado durante la redacción y para fundamentar el ulterior rechazo; es más, Chirbes (2015 [2002]: 112) se refirió al libro donde figura el texto de Santos Sanz Villanueva en una conferencia pronunciada en 1998: «[...] Francisco Rico y Darío Villanue- 
divide la novela, de las que se excluye el epílogo anterior, dan la idea de obra en elaboración o proceso por su desproporción y desemejanza, pero también generan una forzada sofisticación y una acumulación de digresiones sobre la literatura, el sistema literario y el negocio editorial y artístico en general que lastran el desarrollo argumental ${ }^{10}$. Un caso especialmente ilustrativo se da en la secuencia «21» de la primera parte (Chirbes 1991: 76-83), de la que extraigo un breve ejemplo:

La cotización es la única balanza y no hay reglas morales: hay reglas de mercado. Somos mudos. Es el mercado quien habla con nosotros. [...] Pobres escritores. Son como los curas: aburridos. Se ven obligados a escribir según no sé qué canon moral, y a convertir cada uno de sus mezquinos crímenes en un acto de piedad. Viven de la hipocresía. Me perdonas, ¿verdad, José? No es por ti, cielo. Tú no te tomas las cosas tan a la tremenda. Nadie que sepa conjuntar así los colores del traje con los de la camisa puede ser un ideólogo. Llevas una camisa preciosa. Quizá demasiado bien entonada (Chirbes 1991: 83).

La introducción de estas nociones afecta sobremanera a la caracterización de los personajes de En la lucha final, cuyas reflexiones y comportamientos vienen predeterminados y artificiosamente articulados por el narrador sin nombre. En novelas posteriores, Chirbes armonizó con mayor sutileza todas estas consideraciones basadas en su formación como historiador, la prestigiada sociología de Adorno y en su bagaje como reportero para la revista Sobremesa, y las desarrolló por extenso en prólogos, conferencias, ensayos y entradas de su diario:

Y he tenido la certeza de que también yo me veré obligado a acabar contándole mi parte de trama a otro, a alguien que tenga la inocencia de mentirse suficientemente para creerse sabio tejedor durante algún tiempo: un iluso, o un impostor. [...] Me parece difícil darles forma y, al mismo tiempo, curiosamente, sé que la forma es lo único que puede salvarlos a ellos y salvarme a mí de ellos (Chirbes 1991: 183-184).

\footnotetext{
va, autores de una Historia crítica de la literatura española, publicada en 1992 por la Editorial Crítica: un grueso volumen en el que aparecíamos hasta el último gato de la narrativa [española]». Rico (1992: 91) y de nuevo Sanz Villanueva (1992: 254-260) resaltan la importancia adquirida por la novela negra, policiaca o de intriga. Alonso (1992: 414) ya había adscrito Mimoun a esta tendencia: «Acorde con la trama, la novela adopta una estructura de relato policial donde se dan cita el suspense o la intriga [...] y, sobre todo, un telón de fondo donde se mueven personajes y factores de intriga que llevan a pensar en hampas organizadas [...]». Este especialista no advierte, en cambio, la posible censura de la transición y democracia españolas que recoge un análisis reciente de Serber (2019), lo que demuestra cómo las novelas publicadas posteriormente por Chirbes son decisivas para reinterpretar tanto Mimoun como En la lucha final, sobre la que Thion Soriano-Molla (2015: 3-4) comenta: «Los aspectos que unen al grupo [de universitarios y militantes de extrema izquierda de En la lucha final] son las falsas posturas con las que sus existencias se van desarrollando durante la Transición». En Jacobs (1999: 186) Chirbes declaró: «[en Mimoun] quise representar [a] esa gente que perdió la transición y buscó la salvación individual. [...] En la lucha final quise escribir, en cambio, acerca de la clase social que acababa de llegar a los aledaños del poder».

10 Esto también liga En la lucha final al intimismo y la fragmentación de la novela estructural, fomentada por el nouveau roman francés, afianzada en España por los narradores del «boom latinoamericano», y estudiada por Sobejano (1975 [1970]).
} 
Chirbes tampoco afinó el pulso lingüístico o el impulso verbal de los diálogos y el modelo monologal de En la lucha final, y no volvió a abundar en ello hasta La caída de Madrid, en la que depuró la estructura, el estilo y el tono en los que persistiría en Los viejos amigos, Crematorio y En la orilla. Los juicios de Martín Gaite precisamente apuntan las dificultades de Chirbes para escribir diálogos en novelas anteriores a $L a$ caída de Madrid:

Carmen Martín Gaite me decía que yo no sabía hacer diálogos. Seguramente tenía razón; y, sin embargo, creo que he hecho hablar a algunos personajes. No ya monologar, como lo hacía Carlos en Los disparos del cazador, me refiero a dialogar, como hacen los personajes de La caída de Madrid (Chirbes A ratos perdidos, 2: 72).

Herralde (2006: 79) resaltó que En la lucha final, «pese a fragmentos excelentes [...], estaba lastrada [...] por un elemento de inverosimilitud que [la] [...] aplicada labor [de revisión]» no disipó del todo. Chirbes no supo dotarla de la llaneza y la agilidad lingüística de novelas posteriores, e incurrió en la verbosidad desde la primera línea: «Relucían como joyas, si uno los contemplaba desde lejos, y la verdad es que, en la distancia, llegaron a deslumbrarme» (Chirbes 1991: 9) ${ }^{11}$. A lo largo de las páginas se repiten las florituras verbales para caracterizar la impostura, frivolidad o evanescencia de los personajes, pero muchas resultan grandilocuentes y afectadas por la reiteración de conceptos o la acumulación de referentes:

Entraban los últimos rayos del sol a través de las persianas y los muebles de la casa estaban envueltos en una funda de miel [...]. Se borraron los perfiles que definían muros y muebles y él [Pedro] tuvo la sensación de que el suelo sobre el que navegaba la silenciosa cama revuelta no alcanzaba a sostenerlo (Chirbes 1991: 19).

Concha tuvo que levantar su orden contra el grupo. La superficie reluciente de los muebles era el brillo de sus dientes. ¿Cómo voy a entenderla? (Chirbes 1991: 52).

Después le había acariciado el lóbulo [de la oreja de Silvia] sin dejar de sonreír. El pendiente de plata le bailó entre los dedos [...]. Digamos que José Bardón tuvo prisa por tocar la espiga de plata en su lóbulo (Chirbes 1991: 56-57).

Se intuye que la intención de estos lugares es la de mostrar la vacuidad y el lenguaje engolado e impostado de los personajes y del narrador, que también trata de exhibir su

11 En 1998 Chirbes recuperó parcialmente esta idea en una charla en la Universidad de Duisburgo para referirse a la carencia de ideas y de compromiso ético y moral de algunos escritores y novelas, consideradas brillantes por su estilo y fecunda intertextualidad: «[los críticos] admiran aquellos textos que cristalizan las formas anteriores y las dejan brillando como joyas o que las arrojan al suelo y las convierten en pedazos para romper un juego establecido en el código literario y comenzar otro. Yo también creo en eso, pero sólo en parte [...]. Yo, desde luego, no perdería lo mejor de mi vida intentando escribir novelas si se tratase sólo de un juego, de tejer un bordado de ganchillo verbal utilizando los hilos de un género que otros manejaron antes que yo» (en Chirbes 2015 [2002]: 81-83). 
brillantez estilística con ampulosidad. Sin embargo, como en el caso de las reflexiones metaliterarias señaladas, estos pasajes no se ajustan al tono sórdido e indecente del argumento, y más que admiración o deleite por la asociación de referentes, denotan un exagerado gusto de Chirbes por la frase redonda pero un tanto huera y dispersa:

Estaba en el primer escalón, aprendiendo a reconocer a aquella gente un poco del mismo modo que los estudiantes aprenden a reconocer en las ilustraciones del libro de arte el Discóbolo de Mirón, la Venus de Milo o el Torso de Beldevere (Chirbes 1991: 10).

Las confidencias de Amelia la protegían. Digamos que el corazón de Amelia era una maqueta desmontable que le permitía ensayar con lo que estaba escondido en José (Chirbes 1991: 71).

Las palabras de José, su resentimiento contra Ricardo le resbalaron dentro, como las gotas de lluvia resbalaban sobre el cristal de la ventana, y la refrescaron, la hicieron sentirse de nuevo propietaria (Chirbes 1991: 74).

La pureza desata la peor de las sospechas: una sospecha tozuda, insistente, que no muere hasta que destruye el agente que la puso en marcha. La noche que confirmaron que Ricardo era solo humo, todos durmieron en paz (Chirbes 1991: 147).

Todas estas razones debieron de ser las que llevaron a Chirbes a postergar En la lucha final y a replantearse sus aspiraciones comerciales y su técnica como novelista. En sus novelas siguientes las relaciones entre significado y forma y entre contenido, tono y estilo se armonizan más sutilmente y son objeto de reflexión en conferencias, artículos, ensayos y entradas de su diario, en los que se condena la inanidad y sofisticación a las que él mismo se había aproximado en En la lucha final. Así, con la publicación de La buena letra y Los disparos del cazador, Chirbes dio carpetazo a los arabescos argumentales y las tendencias en boga en el mercado literario español por aquel entonces al escribir dos nouvelle centradas en un pasado de España que a juicio del autor quedaba definitivamente solapado en 1992 por los fastos olímpicos y la Exposición Universal de Sevilla. En las dos simplificó la trama, la estructura y el punto de vista, y limitó las digresiones y los alardes estilísticos para focalizar el argumento en los recuerdos de los dos narradores protagonistas, Ana y Carlos Císcar, desde los últimos años de la República hasta finales de los ochenta con el objetivo de relatar y comprender lo sucedido en España entre la guerra civil y la democracia actual.

En La larga marcha y La caída de Madrid, Chirbes perfiló la forma de novelar que le distinguió hasta En la orilla ${ }^{12}$ : la acumulación de técnicas de la novela de finales del XIX y principios del XX (fluir de conciencia, polifonía, analepsis), y del nouveau roman (fragmentación, perspectivismo, recursividad, mise-en-abyme, collage), para tratar de

12 La póstuma París-Austerlitz (2016), cuya primera versión fue desechada para la publicación por el autor en torno al año 1995, supuso una vuelta a la novela corta y al tono emotivo e intimista de La buena letra. 
interpretar la realidad, de dotarla de sentido a partir de un orden y de una construcción determinadas al modo de Galdós, Balzac y de otros autores decimonónicos. Chirbes ensayó todo ello en En la lucha de Madrid, pero no logró la cohesión, equilibrio y justificación argumental y estructural de sus novelas posteriores, en especial de la de Los viejos amigos, con la que aquella presenta mayores concomitancias temáticas y estilísticas, por lo que no sería descabellado considerar Los viejos amigos como la novela que Chirbes hubiese querido culminar cuando redactó En la lucha final.

$$
* * *
$$

Desde luego, y de acuerdo con Español (2019: 236), En la lucha final carece de «la fuerza narrativa de las demás novelas que componen lo que hemos llamado el ciclo chirbesiano». Las páginas anteriores muestran varias de las posibles razones, como el abigarramiento temático y estructural, la endeblez de los personajes, que en ocasiones son un eco demasiado directo del ideario de Chirbes, y la verbosidad excesiva de bastantes pasajes, que emula las tendencias literarias que despreciaría años después ${ }^{13}$. Todo ello explica por qué el escritor se negó a reeditarla y por qué se ha convertido en la novela menos significativa de su trayectoria pese a lo esclarecedora que resulta para su producción, puesto que En la lucha final avanzó todas sus facetas como autor: la del escritor posmoderno que quiso recuperar los presupuestos de la literatura realista y naturalista para proponer una interpretación política, económica y social de la España de los últimos ochenta o noventa años; la del fino estilista, y la del ensayista e ideólogo de sus conferencias, artículos y reportajes de viajes, en los que primó la reflexión sobre la narración.

\section{BIBLIOGRAFÍA}

ALONSO, Santos (1992): “Mimoun", en Varios autores. "La pleamar de los ochenta", Darío Villanueva y otros (intr.). Los nuevos nombres: 1975-1990, Francisco Rico (al cuidado de). Historia y Crítica de la Literatura Española, IX. Barcelona: Crítica, 413-414.

CHIRBES, Rafael (1991): En la lucha final. Barcelona: Anagrama.

(1996): La larga marcha. Barcelona: Anagrama.

(2002): El novelista perplejo. Barcelona: Anagrama.

(2003): Los viejos amigos. Barcelona: Anagrama.

(2010): Por cuenta propia. Leer y escribir. Barcelona: Anagrama.

(2015): El novelista perplejo (1. ${ }^{a}$ ed. 2002). Barcelona: Anagrama.

13 En un artículo publicado en 2007 en la revista Livres Hebdo, Chirbes aseveró: «Con demasiada frecuencia, tengo la impresión de que la novela contemporánea se ahoga en un exceso de aptitudes; agoniza por una sobredosis de inteligencia» (en Chirbes 2010: 212). En 2008 postuló: «Muchos de los escritores que se han prestado a ese juego que llaman el gran mercado se quejan de que, pasado el primer momento, se apaga el brillo de estrellas que buscaron» (en Chirbes 2010: 286). 
(inéd.): A ratos perdidos I (1984-1995). Una habitación en París ${ }^{14}$.

(inéd): [A ratos perdidos 2] (agosto de 1995-octubre de 2005) ${ }^{15}$.

(inéd.): $A$ ratos perdidos $[5]^{16}$.

(inéd.): $A$ RATOS PERDIDOS [6] ${ }^{17}$.

ESPAÑOL CASALLAS, Janneth (2019): "Literatura y Derecho: usos de la memoria en Rafael Chirbes y Laura Restrepo", Ana Gallego Cuiñas (dir.). Tesis doctoral. Universidad de Granada: Granada.

HERRALDE, Jorge (2006): Por orden alfabético. Escritores, editores, amigos. Barcelona: Anagrama.

(2015): "Recuerdo a Rafael Chirbes". Biblioteca Nacional de España. [http:// www.bne.es/es/Actividades/2015/diciembre/recuerdo-a-chirbes.html].

JACOBS, Helmut C. (1999): "Entrevista con Rafael Chirbes", Iberoamericana. Núm: 3-4. Vol. 75-76: 182-187.

LÓPEZ BERNASOCCHI, Augusta; y LóPEz de ABIADA, José Manuel (2011a): "Hacia Crematorio, de Rafael Chirbes. Guía de lectura” Augusta López Bernasocchi y José Manuel López de Abiada (eds.). La constancia de un testigo. Ensayos sobre Rafael Chirbes. Madrid: Verbum, 279-369.

(2011b): "Hacia La larga marcha, de Rafael Chirbes. Guía de lectura". Augusta López Bernasocchi y José Manuel López de Abiada (eds.). La constancia de un testigo. Ensayos sobre Rafael Chirbes. Madrid: Verbum, 179-218.

(2011c): "Hacia Los viejos amigos de Rafael Chirbes. Guía de lectura". Augusta López Bernasocchi y José Manuel López de Abiada (eds.). La constancia de un testigo. Ensayos sobre Rafael Chirbes. Madrid: Verbum, 219-278.

RICO, Francisco (1992): "De hoy para mañana: la literatura de la libertad", Darío Villanueva y otros (intr.). Los nuevos nombres: 1975-1990, Francisco Rico (al cuidado de). Historia y Crítica de la Literatura Española, IX. Barcelona: Crítica, 86-93.

SANZ VILLANUEVA, Santos (1992): "La novela", Darío Villanueva y otros (intr.). Los nuevos nombres: 1975-1990, Francisco Rico (al cuidado de). Historia y Crítica de la Literatura Española, IX. Barcelona: Crítica, 249-284.

SERBER, Daniela (2019): "Mimoun de Rafael Chirbes: Ecos y espejos de la España de la Transición”. Cécile Iglesias y Catherine Orsini-Saillet (dirs.). Hispanística $X X$ : Regards sur le paysage. Monde hispanique contemporain. Binges: Orbis Tertius, 183-199.

SOBEJANO, Gonzalo (1975): Novela española de nuestro tiempo (en busca del pueblo perdido), Prensa Española (1. ${ }^{\text {a }}$ ed. 1970). Madrid: Prensa Española.

14 En la propia cubierta se lee: «Este vale». Se referencian por separado las seis partes de los diarios validadas por Chirbes para su publicación y disponibles para la consulta en la Fundació Rafael Chirbes. Esta primera parte comienza en «Abril de 1984» y concluye con una entrada del «20 de agosto de 1992».

15 El título de $A$ ratos perdidos no figura en la cubierta de la versión manejada. La primera entrada es del «5 de agosto de 1995»; la última del «1 de marzo» de 2005.

16 En la parte superior derecha de la cubierta se escribe: «Esta vale». La primera entrada es del «8 de enero de 2007»; la última del «27 de agosto de 2008».

17 En la parte superior derecha de la cubierta se indica: «Este sí». La primera entrada es del «30 de agosto de 2008»; la última del «9 de agosto de 2015». Otra de las versiones del diario concluye en junio. 
THION SORIANO-MOLLA, Dolores (2015): «Desmemoria, posturas e imposturas en la transición en las primeras obras de Rafael Chirbes», Siglo XXI. Literatura y cultura españolas. Vol. 13: 1-13. [https://revistas.uva.es/index.php/ sigloxxi/article/view/1506].

VAL, Fernando del (2014-2015): "Biocronología de Rafael Chirbes", Turia: revista cultural. Vol. 112: 280-305.

VALLS, Fernando (2014-2015): "La narrativa de Rafael Chirbes: entre las sombras de la historia", Turia: revista cultural. Vol. 112: 127-145.

\section{PERFIL ACADÉMICO Y PROFESIONAL}

Jacobo Llamas Martínez ha sido investigador y docente en las universidades de Santiago de Compostela y Neuchâtel. Entre sus publicaciones destacan el estudio Tradición y originalidad en la poesía funeral de Quevedo y las ediciones anotadas de Melpómene, musa tercera de El Parnaso español de Francisco de Quevedo, y de El rústico del cielo, una comedia de Lope de Vega, pero ya lleva varios años compaginando sus investigaciones ecdóticas, métricas y sobre tradiciones literarias en Quevedo y Lope con el estudio de la obra de autores como Rafael Chirbes. En la actualidad trabaja como profesor de Educación Secundaria.

Fecha de recepción: 19-01-2021

Fecha de aceptación: 02-02-2021 